\title{
CHRISTOPH MECKEL: RETRATO FALADO Um documento sobre os descaminhos da Alemanha
}

\author{
Elvira Horstmeyer \\ Universidade Federal do Paraná
}

RESUMO

Este artigo é uma leitura Imanente do livro de Christoph Meckel Suchbild. tber meinen Vater. No inicio, apresenta um esboço histórico sobre as tendèncias da literatura alem $\vec{a}$ desde 0 inicio dos anos 60 .

\section{Esboço histórico}

A literatura alemã da década de 60 e a nova subjetividade

A literatura alemã da década de 60 foi marcada por uma tendência politizante. Enquanto Hans Magnus Enzensberger e Erich Fried escreviam poesias de cunho essencialmente político, Wolf Biermann compunha e apresentava em festivais populares as suas cançōes de protesto (Protestsongs). No âmbito da dramaturgia, surgiu o teatro documental que se dedicava à elaboração do passado histórico, com peças como "O interrogatório" (Die Ermittlung) de Peter Weiss, que tematiza o processo de Ausschwitz. $O$ caráter realista estendeuse também à prosa, onde sobressaem autores como Rolf Dieter Brinkmann, Günther Eich e Max Frisch. Deve-se mencionar também o "Grupo 61", interessado na divulgaçāo da literatura operária, ou seja, de obras escritas por operários sobre as condições de produção nas indústrias. Max von der Grün é um de seus representantes.

A inteligência literária situava-se politicamente à esquerda e estava imbuida de "impaciência revolucionária", aspirando à mudança do sistema político e daí ao surgimento de uma nova sociedade. Não tardou a reconhecer que não teria apoio na base da população. O movimento se exauriu, enquanto os mais radicais se articularam com grupos terroristas, cujos atos espetaculares marcaram o final da década. 
Com o esvaecimento dos ideais revolucionários, os escritores se voltam novamente ao próprio eu. Assim, no final dos anos 60, começa uma outra fase da literatura: a da Nova Subjetividade. Temas de natureza existencial como o nascimento, a infância, o amor, a doença e a morte marcam a produção literária contemporânea. A Nova Subjetividade se manifesta em diversas tendências. No presente contexto, cabe ressaltar uma que, inicialmente controvertida, acabou por se constituir numa fonte aparentemente inesgotável de inspiraçăo: a tondência autobiográfica. Nela o princípio da autenticidade, postulado pela literatura documental do periodo anterior, se encontra com a referência ao próprio eu. O princípio da autenticidade se define agora como uma maneira verídica de documentar a subjetividade humana. $O$ pai, a mãe ou outro membro da família que influenciou a vida do autor são personagens centrais das obras, cujo "documento" principal é a memória do escritor. Fala-se numa literatura de memória. Os autores reiteram sua intençāo de expor diretamente ao leitor, abandonando o recurso da transferência para enredos e personagens ficcionais, suas histórias individuais, seus conflitos internos, suas experiências dolorosas, seus com. plexos de culpa. A escritura autobiográfica constitui-se, enfim, num processo de auto-reflexāo.

Alguns autores que publicaram livros autobiográficos:

Christa WOLF, "Modelo de uma Infância" (Kindheitsmuster), Peter HARTLING, "Divida de amor" (Nachgetragene Liebe), Elisabeth PLESSEN, "Comunicado à Nobreza" (Mitteilung an den Adel), August KUHN, "Minha Măe 1907" (Meine Mutter 1907), Christoph MECKEL, "Retrato Falado" (Suchbild. Uber meinen Vater).

\section{O "Retrato Falado"}

Um dia Christoph Meckel encontra os Diários de Guerra de seu pai. As revelações dos diários tornam-se impulso irresistivel para a decisão de escrever um livro sobre esse homem. Partindo dos diários, o autor faz uma trajetória em dois sentidos:

Como homem contemporâneo, procura reconstruir o perfil de um personagem histórico - Eberhard Meckel, escritor e crítico de teatro, Tenente durante a Segunda Guerra Mundial. A medida que descreve o papel desempenhado pelo cidadão e literato sob o nazi-fascismo, o biógrafo retrata uma "Weltanschauung" significativa para determinada camada de intelectuais dos anos 30 .

Como filho, Christoph procura a imagem do pai. Caminha memória adentro até as profundezas de sua origem, in. 
fância e juventude. Pelo recurso da montagem (lembranças, citações dos Diários de Guerra, dados biográficos e reflexões sobre o caráter do pai) o filho delineia a imagem paterna.

No ponto de convergência das duas trajetórias surge o perfil do homem Eberhard Meckel.

O escritor faz uma composição estilística perfeita, numa linguagem que procura a objetividade. Com a consciência contemporânea, presente nessa linguagem, empreende uma análise radiográfica do passado, perpassada por um forte tom de julgamento. Crueldade do filho com o pai que já nāo vive para poder se defender?

Por várias vezes, o autor interrompe a narrativa para registrar suas reflexões sobre o tema de seu livro. Significativamente, conclui que a busca da objetivação pela linguagem é, antes de tudo, um processo de criação de linguagem. Escrever sobre uma pessoa significa: destruir a realidade de sua vida em favor da autenticidade de uma linguagem. ${ }^{1}$

A tentativa de criação de uma linguagem autêntica, escolhendo por tema o próprio pai, encerra a contradição inerente a toda busca de objetivação da subjetividade. $O$ retrato do pai é essencialmente uma imagem interna do filho. $O$ que resta do homem vivo? $O$ que se vislumbra dele através da engrenagem das frases? Talvez uma leve idéia de seu caráter, os contornos fugazes ou duradouros de uma imagem. ${ }^{2}$

A decisão de escrever sobre o pai é a resposta a um apelo da consciência, desencadeado pelas revelações dos diários. Depois que li seus Diários de Guerra, não posso deixar o caso como está; ele não é mais particular. ${ }^{3}$

Nesse momento, o gesto de Christoph Meckel se torna caracteristico para toda uma geração. Muitos escritores contemporâneos estão empenhados em contribuir com "casos particulares" para a elucidação e o questionamento permanente do período mais lúgubre da história alemã recente: o nacionalsocialismo. Ocorre que o relato de experiências individuais na literatura alcança dimensões inéditas do passado. A literatura de memória revela os preceitos que governavam a vida particular das familias, o relacionamento entre pais e filhos, a formação dada pela familia ao futuro cidadão.

1 MECKEL, Christoph. Suchbild; über meinen Vater. Frankfurt/Main. Fischer Taschenbuch Verisg, 1983. "Uber einen Menschen schreiben bedeutet: das Tatsaechliche seines Lcbens $z$ u vernichtrn um der Tatsaechlichkeit einer Sprache willen." O Retrato Falado ainda nåo está traduzido para o portugués. A traduçăo das citaçōes é livre e se destina unicamente ao contexto deste trabalho.

2 "Was bleibt ubrig vom lebendigen Menschen? Was wird von ibm sichtbar im Triebwerk der Saetze? Vielleicht eine Ahnung von seinem Charakter. die flüchtigen oder festen Konturen eines Suchbildes.' (p. 55)

3 "Beit ich seine Kriegstagebucher las, kann ich den Fall nicht auf sich beruhen lassen; er ist nicht laenger privat." (p. 44) 
Os Diários de Guerra revelam a Christoph facetas assustadoras da vida do pai, da sua atuação sob o regime nazista, enquanto cidadão e representante da camada intelectual da sociedade. Estranhamente, o pai omitira da família a verdade, usando de toda sorte de subterfúgios.

Pelo que dizia era impossível saber o que havia feito e pensado durante o período nazista. Seu papel no contexto geral permaneceu obscuro. $O$ que contava permanecia anedótico: os horrores da guerra - VOCES NEM PODEM IMAGINAR! Nós não podíamos imaginar e acreditávamos nele.t

O filho descobre na mentalidade do pai os elementos que levaram esse homem a deixar-se seduzir pela ideologia da época: Eberhard Meckel era um intelectual desinteressado em política. Seu pensamento estético reduzia-se às categorias do "belo" e "maravilhoso" e estava imbuído de uma crença ingênua e inabalável nos "eternos valores" da cultura germânica. Como alemão, fazia um conceito idealizado de seu país e exaltava os ideais militares da tradição prussiana. Enquanto o conceito de "ideologia" não alcançava sua consciência, as anotações em seus diários vão se impregnando mais e mais do ideário nazista. A escola ideológica, feita sob medida para a sua maneira de pensar, produziu estranhos encadeamentos. Por exemplo, sua convicção de pertencer a uma elite intelectual gerou o pensamento racista. Ia levar algum tempo ainda para o polonês ser digno do alemão ( . . . . ${ }^{5}$

Como, em princípio, não pretendesse apoiar o Estado nacionalsocialista e nem a guerra, Eberhard Meckel protelou quanto pôde seu alistamento no exército, ajudado por seu editor. Mas, quando foi convocado, superou suas reservas inspirado em sentimentos patrióticos. Para o "soldadāo alemão" a defesa da pátria amada era o mais elevado dever de honra. Entretanto, a vida de soldado era totalmente inadequada às suas condiçōes, exigindo extraordinário esforço de adaptação. Os exercícios militares eram maçantes, mas como "disciplina era uma questão de honra", acabou por se adaptar. Nos cursos teóricos, chamava a atenção dos superiores por sua participação e seus conhecimentos. Sentia-se feliz com os elogios do capitão. Tornou-se um excelente atirador. Passado o primeiro ano de treinamento, já sentia orgulho de

4 Aus dem. was er sagte, war nicht zu crfahron, was er gedacht hatte. Beine Rolle im grossen Zusammenhang wurde nicht deutlich. Was er erzaehltc. blleb anekdotisch: die Bcheuss]ichkeiten des Rrieges - IHR HABT KEINE AFNUNG! Wir hatten kelne Ahnung und slaubten ihm. (p. 85)

5 "Das dauerte noch eine Zeit, bis der Pole des Deutschen wirdig war, (...)" (D. 47) 
seu desempenho. Sempre que possivel, isolava-se para escrever poemas, procurando manter a continuidade de sua vida anterior.

Como soldado, submeteu-se à autoridade dos superiores (...) porque a autoridade era um ponto fixo que ele jamais colocou em dúvida. ${ }^{6} \mathrm{Um}$ dia, sentiu que podia fazer carreira. Cabo - capitão - tenente. Da condição de subalterno, passou ao exercício da autoridade. Sentiu que gostava de comandar. A autoridade modificou sua ótica. Por baixo do invólucro estético, apareceu o chauvinismo do oficial. Carreira militar e belas letras - ambivalência fantasmagórica de uma geração.

A guerra se afigurava a ele como uma catástrofe incompreensivel, um golpe fatal do destino. Em momento algum questionou a legitimidade dessa guerra. Sua maneira de pensar condicionava-o a suportar tudo a qualquer preço, NO CUMPRIMENTO AMARGO DO DEVER E DA HONRA PELA PATRIA. ${ }^{8}$

$O$ intelectual de elite considerava Hitler uma vergonha para a Alemanha e nunca se filiou ao partido. Esse fato e o de não participar do debate político diário, refletem uma postura típica de muitos intelectuais da época. A política era negócio para os outros, essa palhaçada suja. Mantinham-se intactas as esferas do intelecto. ${ }^{3}$ Cristoph $\mathrm{Meckel,} \mathrm{o} \mathrm{cidadão}$ contemporâneo, esclarecido e politicamente consciente, constata: Ele [meu pai] cantou e marchou conforme com o Reich Alemão (nunca com Hitler nem com a SS, nem com o partido nazista), ele aprovou a expansão violenta. ${ }^{10}$ Assim, Eberhard Meckel é figura representativa do intelectual que se deixou mistificar pelo nazismo. Embora reprovasse o Führer, tornouse instrumento de sua politica por omissão, por falta de resistência ao regime.

Nos três anos passados num campo de prisioneiros de guerra, Eberhard Meckel encontra tempo para refletir.

Foi ali que se deu conta - PROFUNDAMENTE ABALADO - da existência da culpa alemã coletiva. (...) Mas sua participação pessoal nessa culpa -

6 "(...) well Autoritaet ein Fixpunict kar. den er niemals in Frage stellte"" (p. 48)

7 "Militaerkarriere und Rüczue in schoene Verse - gespenstische Ambivalenz einer Generstion." (p. 28)

8 “Beine Gesinnung verpflichtete inn zum Durchhalten um jeden Preis, IM BITTEREN ERFULLEN VON EHRE UND PFLICHT FUER DAS VATERLAND."' (p. 52)

9 "Polltik war das Geschaeft anderer Leute, alles in allem ein schmutzicer Zauber. man hlelt die Raeume des Gelstes daron frei." (p. 32)

10 "Er saur und marschicrte Konform mit dem Deutschen Reich (durchaus nicht mIl Hitler. BS und NS-Partei), er bejahte die gewaltsame Expansion." (p. 49) 
NÃO. Ele dera o melhor de si e só quisera o bem. Culpa individual estava fora de cogitação. ${ }^{11}$

O idealista que acreditara inabalavelmente no triunfo da causa alemã e na superioridade germânica, apercebe-se gradualmente do grave comprometimento de seu país e sua "Weltanschauung" passa por uma dura prova. Três capítulos do "Retrato Falado" tratam da luta de Eberhard Meckel consigo mesmo. A tomada de consciência sobre o verdadeiro papel que ele desempenhara na guerra exige uma reformulação profunda na sua maneira de pensar. Exige que ele admita seu envolvimento pessoal na culpa coletiva da Alemanha.

A questão da culpa alemã não lhe dava sossego. Ele só encontraria respostas quando deixasse de afirmar quão honrosa fora sua conduta. Mas ele não abriu mão de seu aưoconceito de honradez.12

Voltando a sua cidade natal após a guerra, Eberhard Meckel reúne a família e retoma suas atividades como crítico de arte, escrevendo resenhas para um jornal local. A partir daí, Christoph Meckel descreve um homem nervoso, irascivel, preocupado em restabelecer sua autoridade na família. Homem talentoso, acostumado à introjeção, Eberhard Meckel não pode furtar-se à idéia da culpa, que insiste em vir à tona, exigindo permanente recalcamento. Pois, em seu conceito de autoridade, rígido e imutável, dizer francamente à família que fora nazista resultaria na perda da sua posição.

Foi o dilema de meu pai que os seus conceitos há muito obsoletos de pátria, arte e familia fossem pervertidos pelo Terceiro Reich e portanto aniquilados; mas ele, ao voltar ferido da guerra e da prisão, dependia cada vez mais desses mesmos conceitos..$^{13}$

Em seu desempenho como escritor, Eberhard Meckel mantém uma postura inalterável. A guerra não conseguiu

11 "Dort sties; er - IM INNERN BENEGT - mit der Erkenntnis zusammen, dass deutsche Kollektivschuid vorhanden war. (...) Aber persoenllches Verschulden NEIN. Er hatte das Edle gewollt und sein Bestes getan. Persoenliche Bchuld stand nicht zur Debatte." (p. 60-61)

12 "Die Frage nach deutscher Schuld liess inm keine Ruhe. Sle war nicht zu beantworten ohne die Prelsgabe seiner mit Nachdruck behaupteten, persoenlichen Rechtschaffenheit. Aber er gab selne Rechtschaffenheit nicht preis." (p. 85)

13 "Es war das Dilemma meines Vaters, dass seine lange schon iberlebten Vorstellungem von Helmat. Kunst und Familie durch das Dritte Reich pervertiert, infolgedessen erledigt wurden, er selbst aber, zerstoert aus Krieg und Gefangenschaft kommend, in immer staerkerer Weise auf sie angewiesen war." (p. 111) 
modificar seu esteticismo romântico e ele continuou pela vida afora buscando elevação no "belo", "sublime" e "nobre". O crítico de teatro não tomou conhecimento da nova literatura (Brecht) que emergia a sua volta. Não há em seu trabalho nenhum pensamento, nenhuma imagem ou noção de mundo ou humanidade que transponha os conceitos tradicionais de pátria, honra, mulher e filhos, e da efemeridade das coisas terrenas. ${ }^{14}$

Eberhard Meckel, o pai, é apresentado como o exemplo típico do CHEFE DE FAMILIA. Dirige a família obstinada. mente conforme com os tradicionais preceitos burgueses. $O$ primeiro filho (...) era menino, o primogênito só podia ser menino. No pensamento familial rígido de meu pai só um menino era realização, confirmaçāo, orgulho. ${ }^{15} \mathrm{~A}$ familia é o seu refúgio e o fim de todas as suas aspiraçōes. Mais importante que qualquer evento da época era a vida diária em sua casa, a familia e o apoio que ela lhe dava $(. .)^{16} \mathrm{E}$ é na familia que o CHEFE exerce o poder. O filho torna-se objeto de uma educação severa, entendida como necessária ao aprendizado da ordem, obediência e disciplina. As pancadas vinham impiedosas e precisas, contadas baixinho ou em voz alta $(\ldots)^{17}$

Após os abalos da guerra, tornava-se imprescindível uma mudança de conduta, uma reformulação dos velhos conceitos patriarcais. Mas Eberhard Meckel nāo conseguia desempenhar na familia outro papel que não o do "patriarca", o do senhor absoluto e inquestionável. Para o filho, que passara oito anos separado dele, a desilusāo é profunda. O semideus de minha infância era um homem nervoso, um educador sequioso de exercer a autoridade. ${ }^{18}$ Esse pai causa muito sofrimento à familia e o filho passa a evitá-lo, procurando satisfazer fora de casa as necessidades da infância. Eu não o procurava mais."

Somente num breve período da vida, pai e filho vivem o encontro. São os primeiros quatro anos de vida de Christoph. Curtos, muito enfáticos, são os trechos do livro que contam esse tempo. Foi a sua melhor época para a criança,

14 "Es gibt in selner Arbeit keinen Gedanken. keine Vorstellung und keine Idee von Welt oder Menschsein, die über herkoenmliche Begriffe wie Heimat. Vaterland, Ehre. Frau un Kind und die Vergaenglichkett alles Irdischen hinausreicht." (p. 111)

15 "Das erste Kind (...) war ein sohn. ds erstzeborene durfte nur ein sohn seln. Im starren Famillendenkcn meines Vaters war nur ein Sohn Erfullung. Bestaetigung. Stolz." (p. 34)

16 "Wichtlger als alles zeltgeschehen war das taegliche. naechtliche Leben in seinem Haus, die Famille und ras sie an Rückhalt für inn hergab (...)" (p. 34)

17 "Dle Prusel erfolgten gnadenlos und praezis, laut oder leise sezaehlt $1 . \ldots$ " (p. 39)

18 "Der Halbeott des Kinderglaubens war ein nervoeser Mann, Erzteher mit Nachholbedart an Autoritaet." (p. 74)

19 "Ich sing als Kind nicht mehr zu ihm hin." (p. 74) 
e a melhor da criança para ele. Quatro anos de realização quase perfeita..$^{\circ}$ Pouco depois começam as medidas disciplinares destinadas à educação do menino, que destróem definitivamente a breve felicidade do encontro. Ele dominava uma espécie de sistema de castigos $(\ldots)^{21}$

Christoph Meckel cresce, deixa a casa paterna e procura viver sua própria vida. Começa a pintar e a escrever poemas. Ao tomar conhecimento das atividades artísticas do filho, o pai profere uma dura sentença: Não se iluda com seu talento. Você não tem talento. ${ }^{22}$ Mas Christoph publica suas poesias, ganha projeção pública e amplo reconhecimento pela crítica. O sucesso literário do filho é um golpe fatal para o pai. Na vertigem da identidade diluída, ele, o lírico, perdia sua posição. ${ }^{23} \mathrm{E}$ a partir de então, não consegue mais escrever, alimentando o espírito com a produção literária do filho. VOCE ESCREVE AS POESIAS QUE EU GOSTARIA DE TER ESCRITO. ${ }^{24}$

A essa altura, o conflito pai-filho atinge seu ponto culminante. $O$ triunfo literário do filho sobre o pai constitui o eixo da narrativa. O "Retrato Falado", em sua perfeição estilística, é a própria expressão do triunfo. Segundo o crítico Horst KRUGER, é a obra literária mais forte do autor, a que lhe dará novo perfil e nova projeção literária.

Outro foco narrativo leva o leitor à infância de Eberhard Meckel. Christoph conta a infância do pai estabelecendo paralelos com a própria meninice. Infere-se que as concepções sobre educação têm uma longa tradição na história da familia alemã burguesa. O pai de Eberhard Meckel, que exercia uma autoridade despótica na familia, aplicava um método educativo baseado em menosprezo, em ordens e castigos físicos.

Você não é nada e não sabe nada.

Vá fazer suas lições.

(...) que fazia imperar a frieza e

a ordem e espancava seus filhos

no porão..25

20 "Es war seine beste zeit für das Kind, und es war die beste Zeit des Kindes fur ihn. Vier Jahre fast uneingeschraenkter Verwirklfchung:" (p. 35)

"Der beherrschte so etwas w'ie eln Bystem von Strafcn (....)" (p. 39)

"Bilde dir nicht eln, begabt zu sein. Du bist nicht begabt." (p. 102)

"Im Taumel aufaeloester Identitaet verlor er, als Lyriker, seine Position." (D. 103)

"DU SCHREIBST DIE: GEDICHTE, DIE ICH SCHREIBEN WOLLTE." (p. 103)

"Du bist nichts, du kannst nichts. macir deine Echulaufaaben.

(...) der Eis und Ordnung waltsn liess und selne Soehne im Keller verprügelte" (p. 18) 
Ao pequeno Eberhard faltou a compreensão para as suas necessidades de criança, faltou o afeto, faltou a dedicação do pai. Aniquilado, [meu pai] saiu do abismo de sua infância. ${ }^{26}$

Chama a atenção o fato de que certas atitudes de submissāo exigidas à criança retornam mais tarde na postura do cidadão Eberhard Meckel perante o Estado. A autoridade era um fato que ele aceitava de uma maneira sutil e quase imperceptivelmente submissa." E, como pai, Eberhard Meckel aplica no filho as mesmas regras disciplinares com que fora educado. Em nome da ordem, obediência e humanidade, a fim de que houvesse justiça e a justiça se fixasse na mente da criança, foi instituída a pena do espancamento. ${ }^{28}$

$O$ texto sugere que a identificação de Eberhard Meckel com o pai cruel e autoritário criara nele os condicionamentos para o "sucesso" de sua carreira militar e que o embrutecimento gradativo do oficial sob o regime nazista constituíra o marco final da trajetória iniciada na infância. Ele sempre aceitara tudo - por conduta e temperamento - ele aceitara seu pai, depois seu país $(. .)^{29}$

$\mathrm{Na}$ estrutura familiar - o pai no papel de CHEFE supremo e incontestável - reflete-se a estrutura do Estado nazista. Com a derrota desse Estado, a credibilidade dos CHEFES DE FAMILIA fica profundamente abalada e o conceito tradicional de paternidade perde a sua solidez. Sua prostração torturava os filhos (eles ainda não sabiam que essa paternidade - o déspota destronado e desnorteado - era característica de toda a geração) . $^{30}$

Nesse ponto convergem as linhas narrativas do texto. $\mathrm{O}$ retrato do personagem histórico e a imagem do pai são uma única e grande desilusão. De um lado, o trágico aniquilamento de uma "Weltanschauung", do outro, o fracasso total de uma paternidade.

26 "Geschlazen kroch er aus dem Loch seiner Kindheit." (p. 1a)

27 "Autoritaet war eine Gegebenheit, die cr auf eine sehr subtile, kaum kahrnehmbare Art der Cnterwerfung bestaetigte.', ip. 48)

28 "Im Binn von Ordung. Gehorsam und Menschlichkeit, damit Pecht geschaehe und das Recht sich dem Kind einprsege, Furde die Prügelstrafe eingefuhrt." (p. 39)

29 "Er hatte - durch Verhalten und Wesensart schon immer allcs moecliche bestaetigt. Er hatte seinen Vater bestaetigt. danach sein Vaterland 1....)" (p. 48)

30 "Beine Zerbrochenheit quaelte die Kinder isle wussten nocn nicht. dass diese Vaterschaft der entthronte. hiflos gewordene Despo: bezeichncnd war fur die ganze Generation)." (p. 30) 


\section{Apêndice \\ Dados biográficos}

EBERHARD MECKEL: Nasceu em Freiburg em 1907. Em 1929 mudouse para Berlim. Na década de 30 , escreveu poesias, contos, peças radiofónicas e resenhas. Participou de congressos literários. Publicou seus trabalhos em antologias da época. Convocado para o exército em 1940, fez carreira militar. De 1944 a 1947 viveu num campo francês de prisionciros de guerra. Retornando a Freiburg, tornou-se colaborador na seção de cultura de um jornal local. Escreveu excelentes resenhas de livros, teatro e filmes. Suas pesquisas sobre o poeta Johann Peter Hebel garantiram-lhe um lugar na historiografia lite. rária alemã.

Morreu em 1962.

CRISTOPH MECKEL: Nasceu em 1935 em Berlim. Viveu sua infância em Freiburg, tendo assistido à destruição da cidade em 1944. Viajou pela Europa, Africa. Em 1954/55 estudou Artes Gráficas na Academia de Arte de München. Publicou suas primeiras poesias. Como artista gráfico, expós mais de 30 vezes na Europa, em Teerä, na Africa e nos EEUU.

Em 1980, publicou o RETRATO FALADO.

\section{REFERENCIAS BIBLIOGRAFICAS}

1 HEISE, E. \& ROHL, R. História da literatura ąlemā. São Paulo, Ática, 1986. $94 \mathrm{p}$.

2 KRUGER, H. Ein Dokument, ein kleines Denkmal deutscher Irrwege. Frankfurter Allgemeine Zeitung, Frankfurt, 1. Apr. 1980.

3 MECKEL, C. Suchbild, über meinen Vater Frankfurt/Main, Fischer Taschenbuch Verlag, 1983. $126 \mathrm{p}$. 